\title{
Development of clinical utility of zoledronic acid and patient considerations in the treatment of osteoporosis
}

This article was published in the following Dove Press journal:

Patient Preference and Adherence

29 June 2010

Number of times this article has been viewed

\section{Johann D Ringe}

Direktor der Med. Klinik 4, Allgemeine Innere, und Westdeutsches Osteoporose Zentrum (WOZ), Klinikum Leverkusen $\mathrm{gGmbH}$, Leverkusen, Germany
Correspondence: Johann D Ringe Direktor der Med. Klinik 4, Allgemeine Innere, und Westdeutsches Osteoporose Zentrum (WOZ), Klinikum Leverkusen $\mathrm{gGmbH}, \mathrm{Am}$ Gesundheitspark I I, 5 I 375 Leverkusen, Germany

$\mathrm{Tel}+02|4 /|$ 3-229 |

Fax +02 I4//3-2294

Email ringe@klinikum-lev.de

\begin{abstract}
Osteoporosis is a major health concern, which results in the increased risk of fractures. There is a high risk for the first or consecutive fractures leading to considerable morbidity and debilitating consequences if osteoporosis is untreated. Currently, bisphosphonates are the mainstay of treatment for osteoporosis though long-term persistence and adherence to bisphosphonates, especially those taken orally, remain low. This medication noncompliance has serious consequences on osteoporotic patients as it is associated with a significantly higher fracture risk. Intravenous (IV) zoledronic acid (ZOL), developed to increase compliance by overcoming the frequent and burdensome dosing requirements of oral bisphosphonates, is the first and the only once-yearly bisphosphonate globally approved for use in the treatment of up to 6 indications of osteoporosis. Several clinical studies have documented that a single infusion of IV ZOL resulted in decreased bone turnover and improved bone density for at least 12 months post infusion. This article traces the development of ZOL's clinical utility and evaluates its patient preference by collating data from all major clinical trials, studying the efficacy and safety of ZOL in the treatment of osteoporosis and other benign bone disorders.
\end{abstract}

Keywords: bisphosphonates, patient preference, efficacy, safety, Paget's disease

\section{Introduction}

\section{Osteoporosis}

Osteoporosis, a chronic disease that affects an estimated 200 million people worldwide, is characterized by decreased bone mass, as well as weakened bones, with an increased risk of fractures. Often diagnosed late and subsequent to a fracture, it leads to significant morbidity and mortality. ${ }^{1,2}$ Osteoporosis can be classified into 2 forms: primary and secondary. Primary osteoporosis results from cumulative bone loss as people age and go through changes in their sex hormones. Secondary osteoporosis results from a variety of medical conditions, diseases, or use of certain medications that adversely affect skeletal health. ${ }^{3}$ The World Health Organization (WHO) defines osteoporosis as a bone mineral density (BMD) with a T-score of $\geq 2.5$ standard deviations below the gender-specific young adult mean (ie, T-score $\leq-2.5$ ), as measured by dual energy X-ray absorptiometry (DXA). ${ }^{4}$ However, total fracture risk reflects both BMD-dependent and BMD-independent risk factors, and the new WHO absolute fracture risk algorithm takes into account BMD, age, smoking, alcohol intake, personal or parental history of fracture, body mass index, corticosteroid use, and rheumatoid arthritis to predict individual patients 10 -year probability of sustaining osteoporotic fractures. ${ }^{5,6}$ 


\section{Bisphosphonates}

Bisphosphonates, which inhibit osteoclastic activity, are the most commonly used medications for the treatment of osteoporosis. ${ }^{7,8}$ Several formulations of bisphosphonates are currently available. Alendronate (ALN), risedronate (RIS), and ibandronate are oral bisphosphonates that have been widely used for the treatment of postmenopausal osteoporosis (PMO). These bisphosphonates were originally approved as a once-daily formulation. However, low adherence to daily therapy coupled with recognition of the long skeletal retention of these bisphosphonates led to the evolution of lessfrequently-dosed but bioequivalent formulations. ${ }^{9,10}$ Current bisphosphonate regimens include once-weekly ALN or RIS, once- or twice-monthly ibandronate and RIS, quarterly intravenous (IV) ibandronate, and once-yearly IV ZOL. ${ }^{8}$

\section{Zoledronic acid}

Zoledronic acid (ZOL) (Aclasta ${ }^{\circledR} /$ Reclast $^{\circledR}$; Novartis Pharma AG, Basel, Switzerland), a third-generation bisphosphonate available as an IV formulation (5 $\mathrm{mg}$ given once-yearly, recommended with daily supplementation of 500-1,200 mg elemental calcium plus $400-800 \mathrm{U}$ of vitamin D), is approved globally for up to 6 indications.

i. Treatment of PMO in women to reduce the incidence of hip, vertebral, and nonvertebral fractures and to increase BMD

ii. Prevention of clinical fractures after hip fracture in men and women

iii. Treatment of osteoporosis in men

iv. Treatment and prevention of glucocorticoid-induced osteoporosis (GIO)

v. Prevention of PMO (in the United States)

vi. Treatment of Paget's disease of bone

In May 2009, ZOL was approved by the US Food and Drug Administration for use, once every 2 years to prevent osteoporosis in postmenopausal women with osteopenia in the United States. ${ }^{11}$ ZOL (Zometa ${ }^{\circledR}$; Novartis Pharma AG, Basel, Switzerland) is also approved for the treatment of hypercalcemia of malignancy (HCM) and advanced malignancies involving bone. ${ }^{12}$

This article traces the development of ZOL's clinical utility by collating data from all major clinical trials, studying the efficacy and safety of ZOL in the treatment of primary and secondary osteoporosis and other benign bone disorders. This article also reviews the patient preferences for different osteoporosis medications with a special focus on ZOL. The pharmacology and mechanism of action of ZOL are not reviewed in this article as both have been extensively reviewed previously. ${ }^{13-24}$

\section{Studies evaluating the therapeutic utility of ZOL Clinical studies}

Treatment of PMO

The clinical utility of ZOL in the treatment of PMO was evaluated in 3 randomized and 2 open-label trials.

\section{Early studies of ZOL}

The potential of IV ZOL in the treatment of PMO was initially assessed by Reid et $\mathrm{al}^{25}$ in a placebo-controlled, dose-ranging, 1-year study. This phase II study randomized 351 postmenopausal women aged 45-80 years to receive placebo or one of the following $5 \mathrm{ZOL}$ regimens: $0.25 \mathrm{mg}$, $0.5 \mathrm{mg}$, or $1 \mathrm{mg}$ at 3-month intervals; a single 4-mg dose; or 2 doses of $2 \mathrm{mg}$ administered 6 months apart. Mean lumbar spine and femoral neck BMD was, on average, $4.3 \%-5.1 \%$ $(P<0.001)$ and $3.1 \%-3.5 \%(P<0.001)$, respectively, higher in all the ZOL treatment groups vs the placebo group at the end of the study period. Significant decreases in bone turn over markers (BTMs) were also observed at the end of the study ( $49 \%-52 \%$ decrease in serum type I collagen C telopeptide [CTx] with ZOL vs $8 \%$ decrease in CTx with placebo; $P<0.01$ ). These results indicated that $\mathrm{ZOL}$ infusions given even at intervals of up to 1 year produce similar effects on bone turnover and bone density as those achieved with daily oral dosing with bisphosphonates of proven efficacy against fractures.

The above 1-year trial had 2 consecutive, open-label, 2 -year extension phases. The objective of these extension studies was to assess the long-term efficacy and safety of prolonged use of ZOL for a further 4 years. A total of 119 women who completed the 1-year core study entered the next phase. Majority of the patients who entered the first extension study received $1 \mathrm{mg}$ ZOL every 3 months (total annual dose, $4 \mathrm{mg}$ ), and others with $0.5 \mathrm{mg} \mathrm{ZOL}$ every 3 months (total annual dose, $2 \mathrm{mg}$ ). Patients who entered the second extension study received either calcium only or ZOL $4 \mathrm{mg}$. All patients entering the active treatment arm of the second extension had previously received ZOL $4 \mathrm{mg}$ per year during core and extension 1 studies. Patients received treatment for 2, 3, or 5 years. Study results showed that BMD increased in all 3 subgroups by the end of the 5 -year study period in lumbar spine $(6.4 \%-9 \%)$, proximal femur $(4.9 \%-5.5 \%)$, distal radius $(2.2 \%-3 \%)$, and total body 
(3.6\%-5\%), whereas BTMs decreased. However, there was an insufficient reduction in BTMs and moreover levels of alkaline phosphatase and CTx increased from month 24 onwards in patients treated for up to 5 years. ${ }^{26}$

The long duration of the study allowed trends to be identified regarding the degree of reduction in bone modeling achieved by ZOL and suitability of $4 \mathrm{mg}$ as a total annual dose. The results showed that ZOL $4 \mathrm{mg}$ once-yearly increased BMD and was effective in reducing BTMs over 5 years. However, detailed analysis of BTM changes suggested that the 4-mg dose caused insufficient reduction in remodeling activity and may not suffice to maintain the suppression of bone resorption. ${ }^{26}$ This upward trend in BTMs, leading to insufficient reduction of bone turnover to keep stable reduction in remodeling activity, was similar to a previous trial in which an IV bisphosphonate (ibandronate) was underdosed. ${ }^{27}$ Therefore, the authors concluded that the same mechanism could also play a role in this study and to achieve a more pronounced suppression of bone turnover, a higher IV dose of ZOL might be required. ${ }^{26}$

\section{The health outcomes and reduced incidence with zoledronic acid once yearly-pivotal fracture trial}

The Health Outcomes and Reduced Incidence with Zoledronic Acid Once Yearly-Pivotal Fracture Trial (HORIZONPFT) was a large, international, multicenter, randomized, double-blind, placebo-controlled trial of 3 years duration in which 7,765 patients with PMO were randomized to receive either a 15 -minute IV infusion of ZOL $(5 \mathrm{mg})$ or placebo. ${ }^{28}$ This study showed that ZOL significantly reduced morphometric vertebral, clinical vertebral, hip, and nonvertebral fractures by $70 \%, 77 \%, 41 \%$, and $25 \%$, respectively (Table 1). The 3-year risk reduction (70\%) in the incidence of the vertebral fractures with ZOL exceeded the reduction previously observed for oral bisphosphonates and other therapeutic interventions. ${ }^{28-35}$ Assessment of bone structure and microarchitecture was also performed in a subgroup of patients. Overall, the findings from the study indicated preservation of trabecular bone structure in the ZOL group at 3 years. ${ }^{36}$

\section{First head-to-head study of ZOL vs ALN}

The first head-to-head study involving ZOL and ALN was conducted by McClung et al. ${ }^{37}$ This noninferiority 12-month trial included postmenopausal women (age, 45-79 years) treated with ALN for at least 1 year prior to randomization. A total of 225 patients were randomized (1:1) to receive either a single IV infusion of ZOL $5 \mathrm{mg}$ plus oral placebo or a weekly $70 \mathrm{mg}$ ALN plus a single IV infusion of placebo. The study showed that single-infusion ZOL maintained BMD for 12 months, following the switch from oral ALN in women with osteoporosis (Table 1). At the end of the study period, the ZOL group experienced a $0.12 \%$ (standard error $[\mathrm{SE}]=0.273$ ) increase from baseline in lumbar spine BMD compared with the ALN group that had a $0.828 \%$ (standard error $[\mathrm{SE}]=0.288)$ increase from baseline ( $95 \%$ confidence interval [CI], -1.491 to 0.075$)$. The authors concluded that patients can be switched from oral ALN to ZOL infusion with maintenance of therapeutic effect for at least 12 months.

\section{Effect on bone resorption markers}

Saag et $\mathrm{al}^{38}$ investigated the onset of action and effects on bone resorption markers of a single-infusion ZOL vs weekly oral ALN. The 24-week trial randomized (1:1) 128 postmenopausal women aged 45-79 years to receive either a single IV infusion of ZOL $5 \mathrm{mg}$ plus oral placebo or a weekly oral 70 mg ALN plus a single IV infusion of placebo. The primary end point was the change in $\mathrm{N}$-telopeptide of type I collagen (NTx) at week 1 from baseline. A significantly lower mean urine NTx value was seen in the ZOL group compared with the ALN group at week 1 (15.2 nmol BCE [bone collagen equivalents $] / \mathrm{mmol}$ creatinine and $35.5 \mathrm{nmol} \mathrm{BCE} / \mathrm{mmol}$ creatinine, respectively; $P<0.0001$ ). Overall, ZOL caused a greater and more rapid reduction in BTMs compared with weekly ALN (Table 1). Moreover, results from this study also showed that the majority of patients were more satisfied with the annual ZOL infusion (59.8\%), were more willing to take it for a long period of time $(68.0 \%)$, and felt that the annual infusion was more convenient than once-weekly therapy $(66.4 \%)$.

\section{Prevention of PMO}

$\mathrm{ZOL}$ is also approved for the prevention of PMO. The recommended regimen is a 5-mg IV infusion once every 2 years over no less than 15 minutes. Data from a 2-year, randomized, multicenter, double-blind clinical study $(\mathrm{n}=581)$ showed that ZOL significantly increased BMD at lumbar spine and total hip compared with placebo at month 24 for osteopenic women in early and late menopause. ${ }^{39}$

In another 2-year study in a volunteer sample of 50 postmenopausal women with osteopenia treated with 
ZOL or placebo, ${ }^{40} \mathrm{ZOL}$ decreased mean levels of each of 4 BTMs by at least $38 \%$ (range, 38\%-45\%) for the duration of the study $(P<0.0001)$. After 2 years, BMD was higher in the ZOL group than in the placebo group at an average of $5.7 \%(95 \% \mathrm{CI}, 4.0-7.4)$ at the lumbar spine, $3.9 \%(2.2-5.7)$ at the proximal femur, and $1.7 \%(0.8-2.5)$ at the total body $(P<0.0001$ for each skeletal site). Moreover, between-group differences in BTM and BMD were similar at 12 and 24 months. ${ }^{40}$

\section{Hip fractures}

Hip fractures are associated with increased morbidity, functional decline, and death in older adults. ${ }^{41}$ Mortality is increased with reported rates of $15 \%-25 \%$ in the year following hip fracture. ${ }^{41,42}$ The clinical efficacy of ZOL in patients with a recent, low-trauma hip fracture was investigated in a large, randomized, double-blind, placebo-controlled, multicenter 5-year study known as the HORIZON-Recurrent Fracture Trial (HORIZON-RFT) $(n=2127)$, which is the only trial ever conducted to study the risk of fracture incidence in patients who have already sustained a hip fracture, in which the median duration of follow-up was 1.9 years. ${ }^{43}$ Patients included in the HORIZON-RFT study were men or women aged $\geq 50$ years, who had a low-trauma hip fracture surgically repaired within the previous 90 days. ${ }^{43}$ Patients were randomized (1:1) to receive IV infusions of ZOL $5 \mathrm{mg}$ or placebo once-yearly. The primary measure of efficacy was new clinical fracture (excluding toe, finger, and facial bone fractures, and those occurring in abnormal bone) over the duration of the study. Secondary efficacy measures included new hip fracture, nonvertebral fracture, and vertebral fracture and the change in BMD in the nonfractured hip (measured annually with DXA); and prespecified safety end points, including death.

Data from the study showed that once-yearly ZOL $5 \mathrm{mg}$ IV was effective in reducing the risk of fractures developing in patients who recently had a low-trauma hip fracture (Table 1$).{ }^{43} \mathrm{ZOL}$ significantly $(P=0.001)$ reduced the risk of any new clinical fracture by $35 \%$ relative to placebo, with $8.6 \%$ of $\mathrm{ZOL}$ and $13.9 \%$ of placebo recipients experiencing such fractures at 2 years. ZOL also reduced the risk of most secondary end point fractures. After 2 years of treatment, the risk of nonvertebral (7.6\% ZOL vs $10.7 \%$ placebo recipients) and vertebral fractures $(1.7 \% \mathrm{ZOL}$ vs $3.8 \%$ placebo recipients) were also significantly reduced $(P<0.05)$ by $27 \%$ and $46 \%$ with ZOL relative to placebo, although the treatment groups did not significantly differ in terms of hip fracture risk (2.0\% ZOL vs $3.5 \%$ placebo recipients). ${ }^{43}$
BMD at both the total hip and the femoral neck improved significantly $(P<0.001)$ with ZOL relative to placebo after 12,24 , and 36 months of treatment. Moreover, clinically relevant losses of BMD (based on prespecified measures of bone safety) were observed in $2.4 \%$ ZOL vs $11.9 \%$ placebo recipients. ${ }^{43}$

A significant reduction in all-cause mortality in patients treated with ZOL was also observed: $9.6 \%$ patients in the ZOL group and $13.3 \%$ patients in the placebo group died, a $28 \%$ reduction in deaths from any cause in the $\mathrm{ZOL}$ group $(P=0.01){ }^{43}$

Post hoc analysis of the HORIZON-RFT study to examine whether the timing of the first infusion had any relationship to fracture and mortality benefit showed that patients infused 2-12 weeks after hip fracture, showed significant reduction in clinical vertebral fractures, nonvertebral fractures, and hip fractures, as well as all-cause mortality (first trial ever to show a significant reduction in mortality after using an antiosteoporosis medication). ${ }^{44}$

\section{Male osteoporosis}

Male osteoporosis is an important public health issue and remains largely undertreated in general practice. Moreover, even though men experience fewer osteoporotic fractures than women, they have higher mortality after fracture..$^{45}$ Two analyses provide evidence for the efficacy of ZOL in the treatment of osteoporosis in men, and based on these studies, ZOL was approved in the European Union (EU).

Data analyzed from the male subpopulation of the 3-year HORIZON-RFT trial ${ }^{43}$ showed that ZOL was significantly more effective than placebo in increasing total hip BMD in men at 12,24, and 36 months and in increasing femoral neck BMD at 24 and 36 months. ${ }^{46}$ Though the study was not powered to show a reduction in clinical fractures in men, the 2-year cumulative clinical fracture event rates were $7.45 \%$ and $8.7 \%$ for ZOL and placebo, respectively (Kaplan-Meier estimates). ${ }^{46}$ Moreover, the study showed that men experienced greater absolute mortality benefit than women $(6.4 \%$ vs $2.8 \%$ ), although they had a similar reduction in the risk of death. ${ }^{47}$

A 2-year study randomizing 302 hypogonadal men to annual ZOL $5 \mathrm{mg}$ IV or weekly oral ALN $70 \mathrm{mg}$ demonstrated that the ZOL group had $6.1 \%$ increase in lumbar spine BMD compared with the ALN group that had $6.2 \%$ increase at 24 months. At month 12 relative to baseline ZOL and ALN reduced serum CTx by $52 \%$ and $57 \%$, urine NTx by $54 \%$ and $59 \%$, serum N-terminal propeptide of type I collagen (P1NP) 
by $51 \%$ and $56 \%$, serum bone-specific alkaline phosphatase (BSAP) by $22 \%$ and $25 \%$, respectively (Table 1 ). The majority of subjects preferred once-yearly IV infusion of ZOL $5 \mathrm{mg}$ over once-a-week oral $70 \mathrm{mg} \mathrm{ALN}{ }^{48}$

\section{Pediatric osteoporosis}

The use of bisphosphonates in children with osteogenesis imperfecta is well established. Most of the reports in children are almost exclusively on IV pamidronate, ${ }^{49}$ although successful treatment with the oral bisphosphonates, such as ALN, ${ }^{50,51}$ has also been reported.

In a recently published study in children with osteogenesis imperfecta, patients were switched to ZOL $(0.04-0.05 \mathrm{mg} / \mathrm{kg}$ every 4 months) for a mean of 3.4 years after pamidronate therapy ( $1 \mathrm{mg} / \mathrm{kg}$ per dose every 2 months) for a mean of 3.75 years. Results from the study showed that ZOL appeared to be similarly effective as pamidronate in improving vertebral BMD and in reducing fracture rates implying that ZOL may be considered a potential alternative to pamidronate infusions in this patient group. ${ }^{52}$

\section{Geriatric osteoporosis}

Osteoporosis is for the most part a disease of the aged. Intravenous bisphosphonates are an option in the elderly who cannot tolerate or may have difficulty adhering to oral bisphosphonate therapy. Once-yearly infusion of ZOL may significantly improve adherence, especially in a geriatric population. Post hoc analysis of pooled data from HORIZON-PFT ${ }^{28}$ and HORIZON-RFT ${ }^{43}$ determining the efficacy of ZOL in osteoporotic postmenopausal women aged $\geq 75$ years has shown that once-yearly ZOL treatment over 3 years significantly reduced the risk of any clinical fracture, clinical vertebral and nonvertebral fractures (Table1). These findings provide evidence of the efficacy of once-yearly ZOL $5 \mathrm{mg} \mathrm{IV}$ in osteoporosis patients of advanced age. ${ }^{53}$

\section{Glucocorticoid-induced osteoporosis}

Persistent use of glucocorticoids is a major cause for secondary osteoporosis, leading to bone loss and increased fracture risk. $^{54-58}$ This increased risk is apparent in some patients within 3 months of starting glucocorticoids. ${ }^{56}$ Prevention and treatment of GIO has been established with bisphosphonates. ${ }^{58}$ Recently once-yearly ZOL $5 \mathrm{mg}$ has been approved for the prevention and treatment of osteoporosis caused by long-term use of glucocorticoids.
The approval for the GIO indication for men and women is based on the study showing that annual ZOL $5 \mathrm{mg}$ IV is more effective in treating bone loss than daily oral RIS in patients with GIO. The study investigated both the prevention and the treatment of GIO in 833 men and women (288 prevention vs 545 treatment subgroups). ${ }^{59}$ Over 1 year, ZOL produced significantly greater increases in BMD of the lumbar spine, femoral neck, trochanter, and total hip than RIS. The increase in BMD with ZOL was evident at 6 months, and ZOL was better than RIS at 12 months (Table1). ${ }^{59}$

\section{Thalassemia-induced osteoporosis}

Osteoporosis is an important cause of morbidity in betathalassemia patients. In a study by Otrock et $\mathrm{al}^{60}{ }^{60} 18$ thalassemia patients with osteoporosis were given ZOL $4 \mathrm{mg}$ IV every 3 months over a period of 12 months. Patients on ZOL had a significant increase in their lumbar spine, femoral neck, trochanter, and total hip BMD measurements over the 12-month period. Patients in the control group did not have any significant change in BMD measurements. There was a significant change in the levels of osteocalcin and bone alkaline phosphatase (BAP) and also a significant decrease in the number of painful sites (bone pain) experienced by the patients. ${ }^{60,61}$

In another study, 66 thalassemia patients with osteoporosis were randomized (1:1:1) to receive ZOL $4 \mathrm{mg}$ IV, every 6 or 3 months, or to receive placebo every 3 months, for a period of 1 year. BMD of the lumbar spine, femoral neck, and wrist was determined before and 12 months after treatment. Patients treated with ZOL $4 \mathrm{mg}$ IV every 6 months had no change in BMD; however, there was an increase in BMD with ZOL $4 \mathrm{mg}$ IV given every 3 months. Both regimens of $\mathrm{ZOL}$ reduced pain. ${ }^{62} \mathrm{BMD}$ remained higher than baseline after 24 months of stopping ZOL treatment. ${ }^{63}$

Overall, the data from the above studies suggest that ZOL may be an effective option for the treatment of osteoporosis in thalassemia patients. ${ }^{60-63}$

\section{Localized transient osteoporosis}

Localized transient osteoporosis (LTO; bone marrow edema) is an increasingly diagnosed condition characterized by acute onset of disabling bone pain, which typically occurs at a single skeletal site. Although its etiology is unknown, LTO has been linked to pregnancy and prolonged periods of exercise but with absence of previous trauma or surgical history, as in algodystrophy. Current treatment options are limited in number and provide inadequate efficacy except recent positive experience with IV bisphosphonates. 
A study by Ringe et $\mathrm{a}^{64}$ in 8 patients with LTO showed that ZOL was highly effective in reducing pain, measured by visual analog scale (VAS 1-10). Pain scores decreased from 9.4 (at baseline) to 0.4. BMD was restored with an average increase in the lumbar spine of $4.1 \%$ after 6 months of treatment and in the affected and unaffected hip area by $9.4 \%$ and $3.0 \%$, respectively (difference $6.4 \%, P<0.01$ ), improving mobility and quality of life $(\mathrm{QoL})$ in patients with LTO of the hip.

\section{Paget's disease}

Paget's disease of bone is characterized by a dramatic increase in bone turnover (both formation and resorption) at one or more skeletal sites. ${ }^{65}$ The bone pain, skeletal deformity, pathologic fractures, secondary arthritis, neurologic complications, and deafness that may accompany this disease contribute to its substantial morbidity. Bisphosphonate therapy is the most commonly used treatment for Paget's disease. ${ }^{65}$

In 2005, Reid and colleagues ${ }^{65}$ published results of a pivotal study comparing ZOL with RIS in patients with Paget's disease. The paper combined 2 identical, double-blinded, randomized controlled trials, comparing ZOL with RIS. In the 6-month trial, patients received either a single IV infusion of ZOL $5 \mathrm{mg}$ (177 patients) or a daily $30 \mathrm{mg}$ RIS for 2 months (172 patients). The primary end point was normalization or a $75 \%$ reduction of serum alkaline phosphatase (SAP) levels in 6 months. A pain scale, gait, and QoL measures were assessed as well. At the completion of this study, a greater number of patients treated with ZOL (96\%) achieved the primary end point compared to those treated with RIS $(74 \%, P<0.001)$. Further, ZOL provided patients with a significantly shorter median time to first therapeutic response (64 days ZOL vs 89 days RIS, $P<0.001$ ).

In patients with Paget's disease of bone, normalization of SAP correlates with a longer duration of biochemical remission. SAP levels were normalized in more patients in the ZOL-treated group (88.6\%) than in the RIS-treated group (57.9\%), $P<0.001$. Bone turnover markers, including serum NTx and serum $\beta$-CTx, measuring osteoblast function (bone formation) and urinary $\alpha$-CTx measuring osteoclast function (bone resorption) were all suppressed into the normal range earlier and more consistently in patients treated with ZOL, $P<0.001$ (Table 1).

At a median of 190 days following the formal trial, only $0.9 \%$ of patients on ZOL showed evidence of recurrent disease activity by biochemical markers compared with $25.6 \%$ of patients on RIS, $P<0.001$. Although the study was designed to demonstrate the noninferiority of ZOL compared to RIS in the treatment of Paget's disease, the authors concluded that "ZOL appeared to be superior in terms of the degree of disease suppression, the rate of onset of effect and (on the basis of preliminary data) the persistence of these effects beyond the six-month trial period." In addition, there was a trend toward improved QoL in patients treated with ZOL.

In a follow-up extension trial of the above study published by Hosking et al, ${ }^{66} 152$ patients who had been treated with ZOL and 115 patients who had been treated with RIS were followed for 18 months to determine the length of remission and durability of bone suppression. A sustained therapeutic response was noted in $98 \%$ of those treated with ZOL vs $57 \%$ of those treated with RIS (Table 1).

\section{ZOL in oncology}

Skeletal complications contribute substantially to the burden of disease in patients with bone metastases from solid tumors and in patients with multiple myeloma. Bone metastases are the most common cause of cancer-related pain and often require palliative therapy. ZOL is widely used as palliative therapy in patients with bone metastases secondary to a wide range of solid tumors, including prostate cancer, lung cancer, and renal cell carcinoma. ${ }^{67}$

ZOL received approval for the treatment of bone metastases secondary to all solid tumor types and bone lesions from multiple myeloma based on the results of 3 large, randomized, phase III clinical trials enrolling more than 3,000 patients.

These trials demonstrated that ZOL (4 mg via 15 -minute IV infusion, every 3-4 weeks) effectively reduced the incidence of skeletal complications associated with malignant bone disease for patients with breast cancer, multiple myeloma, prostate cancer, or solid tumors other than breast or prostate cancer. ${ }^{68-71}$ The primary efficacy end point in all 3 trials was the proportion of patients who experienced at least 1 skeletal-related event (SRE), defined as a pathologic fracture, spinal cord compression, radiotherapy to bone, or surgery to bone. Change in antineoplastic therapy to palliate bone pain was also included as an SRE only in the trial evaluating patients with prostate cancer. HCM was included as an SRE in the analysis of secondary end points. The results of these 3 international trials demonstrate that ZOL has significant and durable clinical benefit in reducing skeletal complications for patients with malignant bone involvement from multiple myeloma and a variety of solid tumors, including breast, prostate, and lung cancers. ${ }^{68-71}$ $\mathrm{ZOL}$ is also being studied for the prevention of aromatase inhibitor-associated bone loss in women receiving adjuvant 
hormonal therapy for early-stage breast cancer and also for the prevention of bone loss during androgen-deprivation therapy. ${ }^{72,73}$

\section{Safety and tolerability of ZOL in osteoporosis and Paget's disease}

Data from several clinical trials have demonstrated that IV ZOL is generally well tolerated in patients with osteoporosis ${ }^{28,37}$ and Paget's disease. ${ }^{65,66}$ In the present section, clinically significant adverse events (AEs) associated with the use of ZOL in osteoporosis are discussed. Tolerability data of ZOL vs placebo, ALN, and RIS is also evaluated.

\section{Clinically significant AEs associated with ZOL}

Acute-phase reactions

The most common AEs observed with ZOL are acute-phase reactions, usually characterized by flu-like symptoms, headache, pyrexia, arthralgia, and myalgia. Most of these symptoms occur within the first 3 days after infusion and tend to resolve within several days after administration (Table 2). ${ }^{28,74}$

\section{Hypocalcemia}

The incidence of hypocalcemia (a serum calcium level $<2.075 \mathrm{mmol} / \mathrm{L}$ ) with $\mathrm{ZOL}$ has been reported in some studies, although in most cases it was asymptomatic and transient. ${ }^{28,38,43,65}$ However, in patients with low normal calcium at onset, it is recommend to start with the regular calcium/vitamin D supplementation before the infusion of ZOL.

\section{Renal function}

Evaluation of the renal safety of once-yearly ZOL $5 \mathrm{mg}$ in several studies has shown that administration of ZOL was not associated with any long-term detrimental effects on renal function. Generally, the renal effects were short term, mild, and transient. ${ }^{28,43,59} \mathrm{~A}$ minimal infusion time of ZOL of 15 minutes, however, is mandatory to avoid an impairment of renal function.

\section{Cardiovascular: atrial fibrillation}

Individual studies of ZOL have found an increased incidence of atrial fibrillation (AF); however, larger epidemiological studies have found no increased risk of AF in patients receiving bisphosphonate treatment.
The only study in the HORIZON clinical trial program where AF was significantly increased as serious AE (SAE) was the HORIZON-PFT study; AF, as SAE, was found to be more frequent in patients who received $\mathrm{ZOL}$ compared with placebo $(1.3 \% \mathrm{ZOL}$ vs $0.5 \%$ placebo; $P<0.001) .{ }^{28}$ Of the 50 events that occurred in patients receiving ZOL, 47 (94\%) occurred $>30$ days after infusion, when ZOL was no longer detectable in systemic circulation. Furthermore, electrocardiograms performed on a subset of 559 patients before and 9-11 days after treatment found no differences between the treatment groups.

In the HORIZON-RFT study, which included an older patient population with more comorbidities compared with other osteoporosis trials, the incidence of serious AF was similar with ZOL and placebo (1.0\% ZOL vs $1.2 \%$ placebo). ${ }^{43}$ When ZOL was compared with RIS in patients with GIO, no serious AF was reported in either of the treatment arms. ${ }^{59}$

\section{Osteonecrosis of the jaw}

In patients receiving high cumulative doses of IV bisphosphonates to prevent SRE associated with bone metastases or HCM, cases of osteonecrosis of the jaw (ONJ) have been reported. As most of these patients were also receiving cytotoxic chemotherapy or corticosteroids, it is difficult to determine the true impact of bisphosphonate treatment on risk of ONJ. In patients receiving lower cumulative doses of bisphosphonates for treatment of osteoporosis, very rare cases of ONJ have been reported.

The safety data from the HORIZON-PFT study showed that of the 7,714 patients in the study, there were only 2 cases of possible ONJ: one in a patient receiving ZOL and other in a patient receiving placebo. Both patients experienced delayed healing associated with infection, and both conditions were resolved after antibiotic therapy or debridement. In several other studies with ZOL for the treatment of osteoporosis and Paget's disease, no cases of ONJ were reported. ${ }^{43,59,66}$

Overall, the incidence of ONJ in osteoporotic patients receiving $\mathrm{ZOL}$ is very low, and this can be managed with no special treatment beyond routine dental care. ${ }^{75}$

\section{Tolerability ZOL vs placebo}

Data from the HORIZON trials show that ZOL was generally well tolerated, and there was no significant difference between the ZOL and placebo groups in terms of number of patients who had SAEs, or discontinued follow-up due to an AE. In the HORIZON-PFT study, the number of patients with AEs was significantly higher in the ZOL group (95.5\% ZOL vs 
Table I Summary of key efficacy data for ZOL in the treatment of osteoporosis and Paget's disease

\begin{tabular}{|c|c|c|c|c|}
\hline Study & $\begin{array}{l}\text { No. of patients, } \\
\text { N }\end{array}$ & Study design & Intervention & Key efficacy results \\
\hline $\begin{array}{l}\text { Black et al2 } \\
\text { (HORIZON-PFT) }\end{array}$ & 7,765 & $\begin{array}{l}\text { 3-year, randomized, double-blind, placebo- } \\
\text { controlled clinical trial in postmenopausal } \\
\text { osteoporosis patients }\end{array}$ & $\begin{array}{l}\text { ZOL } 5 \mathrm{mg} \\
\text { placebo }\end{array}$ & $\begin{array}{l}\text { - } 70 \% \text { reduction in morphometric } \\
\text { vertebral fractures over } 3 \text { years } \\
\text { - } 41 \% \text { reduction in hip fractures over } \\
3 \text { years } \\
\text { - } 25 \% \text { reduction in nonvertebral } \\
\text { fractures over } 3 \text { years }\end{array}$ \\
\hline $\begin{array}{l}\text { Lyles et al }{ }^{43} \\
\text { (HORIZON-RFT) }\end{array}$ & 2,127 & $\begin{array}{l}\text { Multicenter, randomized, double-blind, } \\
\text { placebo-controlled, parallel-group } 5 \text {-year } \\
\text { trial in patients who had already sustained hip } \\
\text { fracture; median follow-up was } 1.9 \text { years }\end{array}$ & $\begin{array}{l}\text { ZOL } 5 \mathrm{mg} \\
\text { placebo }\end{array}$ & $\begin{array}{l}\text { - } 28 \% \text { reduction in mortality after hip } \\
\text { fracture } \\
\text { - } 35 \% \text { risk reduction of all new clinical } \\
\text { fractures } \\
\text { - } 46 \% \text { risk reduction of all new clinical } \\
\text { vertebral fractures and } 27 \% \text { risk } \\
\text { reduction in new nonvertebral } \\
\text { fractures } \\
\text { - ZOL improved BMD at total hip and } \\
\text { femoral neck } \\
\text { - ZOL demonstrated fracture } \\
\text { prevention across all patients, even } \\
\text { those at highest risk of fracture }\end{array}$ \\
\hline McClung et $\mathrm{al}^{37}$ & 225 & $\begin{array}{l}\text { I-year, double-blind, double-dummy study in } \\
\text { postmenopausal osteoporosis patients }\end{array}$ & $\begin{array}{l}\text { ZOL } 5 \mathrm{mg} \\
\text { ALN } 70 \mathrm{mg}\end{array}$ & $\begin{array}{l}\text { - Lumbar spine BMD remained stable } \\
\text { with both treatments at } 12 \text { months } \\
\text { - } 78.7 \% \text { of patients preferred a once- } \\
\text { a-year infusion to weekly oral } \\
\text { therapy at the end of study }\end{array}$ \\
\hline Saag et $\mathrm{al}^{38}$ & 128 & $\begin{array}{l}\text { 24-week, multicenter, randomized, } \\
\text { double-blind, double-dummy, active- } \\
\text { controlled trial in postmenopausal } \\
\text { osteoporosis patients }\end{array}$ & $\begin{array}{l}\text { ZOL } 5 \mathrm{mg} \\
\text { ALN } 70 \mathrm{mg}\end{array}$ & $\begin{array}{l}\text { - Significantly greater relative change } \\
\text { in urine NTx values at week I with } \\
\text { ZOL vs ALN } \\
\text { - ZOL group had significantly lower } \\
\text { mean urine NTx values throughout } \\
\text { the } 24 \text {-week study vs the ALN group } \\
\text { - ZOL caused greater and more rapid } \\
\text { reduction in BTMs compared with } \\
\text { weekly ALN }\end{array}$ \\
\hline $\begin{array}{l}\text { Reid et al }{ }^{59} \\
\text { (GIO trial) }\end{array}$ & 833 & $\begin{array}{l}\text { I-year, multinational, multicenter, } \\
\text { randomized, double-blind, double-dummy, } \\
\text { stratified, active-controlled clinical trial in the } \\
\text { prevention and in the treatment of GIO }\end{array}$ & $\begin{array}{l}\text { ZOL } 5 \text { mg; } \\
\text { RIS } 30 \mathrm{mg}\end{array}$ & $\begin{array}{l}\text { - ZOL demonstrated superior BMD } \\
\text { increase at I } 2 \text { months compared } \\
\text { with oral daily RIS in both } \\
\text { subpopulations } \\
\text { - ZOL significantly decreased levels } \\
\text { of } \beta \text {-CTx and PINP compared with } \\
\text { oral daily RIS in both the prevention } \\
\text { and the treatment subpopulations } \\
\text { - } 84 \% \text { of all patients preferred annual } \\
\text { IV over daily oral pills }\end{array}$ \\
\hline $\begin{array}{l}\text { Reid et al }{ }^{65} \\
\text { (Paget's disease- } \\
\text { core studies) }\end{array}$ & 357 & $\begin{array}{l}2 \text { identical, 6-month, randomized, } \\
\text { double-blind, active-controlled trials } \\
\text { in patients with Paget's disease }\end{array}$ & $\begin{array}{l}\text { ZOL } 5 \mathrm{mg} \\
\text { RIS } 30 \mathrm{mg}\end{array}$ & 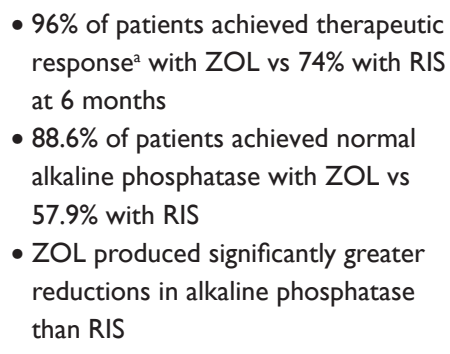 \\
\hline $\begin{array}{l}\text { Hosking et al } \\
\text { (Paget's disease- } \\
\text { extension study) }\end{array}$ & 267 & $\begin{array}{l}\text { Eligible patients from both core studies } \\
\text { reexamined } 24 \text { months after treatment }\end{array}$ & $\begin{array}{l}\text { ZOL } 5 \mathrm{mg} \\
\text { RIS } 30 \mathrm{mg}\end{array}$ & $\begin{array}{l}\text { - } 98 \% \text { of those given } \mathrm{ZOL} \text { maintained } \\
\text { therapeutic response }{ }^{\mathrm{a}} \text { vs } 57 \% \text { of } \\
\text { those given RIS at } 24 \text { months }\end{array}$ \\
\hline
\end{tabular}

(Continued) 
Table I (Continued)

\begin{tabular}{|c|c|c|c|c|}
\hline Study & $\begin{array}{l}\text { No. of patients, } \\
\mathbf{N}\end{array}$ & Study design & Intervention & Key efficacy results \\
\hline $\begin{array}{l}\text { Boonen et } \mathrm{al}^{53} \\
\text { (geriatric } \\
\text { osteoporosis) }\end{array}$ & 3,887 & $\begin{array}{l}\text { A post hoc subgroup analysis of pooled data } \\
\text { from the HORIZON-PFT and } \\
\text { HORIZON-RFT. }\end{array}$ & $\begin{array}{l}\text { ZOL } 5 \text { mg; } \\
\text { placebo }\end{array}$ & $\begin{array}{l}\text { - At } 3 \text { years, incidence of any clinical, } \\
\text { vertebral and non-vertebral fracture } \\
\text { was significantly lower in ZOL } \\
\text { group compared with placebo group } \\
\text { (10.8\% vs } 16.6 \% \text {, I.I\% vs } 3.7 \% \text {, and } \\
9.9 \% \text { vs } 13.7 \% \text {, respectively). }\end{array}$ \\
\hline $\begin{array}{l}\text { Orwoll et } \mathrm{al}^{48} \\
\text { (male } \\
\text { osteoporosis) }\end{array}$ & 302 & $\begin{array}{l}\text { Multicenter, double-blind, active-controlled, } \\
\text { parallel-group study for } 24 \text { months in } \\
\text { hypogonadal men }\end{array}$ & $\begin{array}{l}\text { ZOL } 5 \text { mg; } \\
\text { ALN } 70 \text { mg }\end{array}$ & $\begin{array}{l}\text { - ZOL increased BMD at lumbar } \\
\text { spine, total hip, femoral neck, and } \\
\text { trochanter and was noninferior to } \\
\text { ALN at } 24 \text { months. } \\
\text { - At month } 12 \text {, the median changes } \\
\text { from the baseline of markers for } \\
\text { bone resorption } \beta-C T x \text {, urine NTx } \\
\text { and PINP formation, serum BSAP } \\
\text { were comparable between ZOL and } \\
\text { ALN groups. }\end{array}$ \\
\hline
\end{tabular}

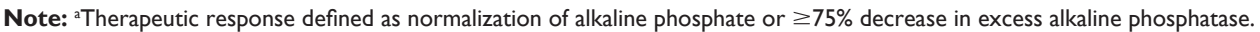

Abbreviations: ZOL, zoledronic acid; HORIZON-PFT, The Health Outcomes and Reduced Incidence with Zoledronic Acid Once Yearly-Pivotal Fracture Trial; HORIZONRFT, HORIZON-Recurrent Fracture Trial; BMD: bone mineral density; ALN, alendronate; NTx, N-telopeptide of type I collagen; BTM, bone turnover markers; GIO, glucocorticoid-induced osteoporosis; $\beta$-CTx, beta-serum type I collagen $C$ telopeptide; PINP, serum N-terminal propeptide of type I collagen; RIS, risedronate; BSAP, bone-specific alkaline phosphatase.

93.9\% placebo; $P=0.002)$, driven primarily by larger number of AEs associated with postdose symptoms. ${ }^{28}$ However, in the HORIZON-RFT study, the difference in the number of AEs between both groups was not significant $(82.3 \% \mathrm{ZOL}$ vs $80.6 \%$ placebo). ${ }^{43}$

The incidence of death was significantly lower in ZOL than that in placebo recipients in the HORIZON-RFT study (9.6\% ZOL vs $13.3 \%$ placebo; $P=0.01$ ), but not in the HORIZON-PFT study (3.4\% ZOL vs $2.9 \%$ placebo). ${ }^{28,43}$

The tolerability profile of ZOL was generally similar to that of placebo with regard to most cardiovascular-related AEs, and no long-term renal toxicity was associated with ZOL in patients from either the HORIZON-PFT or the HORIZON-RFT study. ${ }^{28,43}$

\section{ZOL vs ALN}

The overall incidence of AEs in recipients of ZOL $5 \mathrm{mg}$ IV (once-yearly) was generally similar to that seen in recipients of oral ALN $70 \mathrm{mg}$ once-weekly in a comparative trial of 1 -year duration ( $86.7 \%$ vs $80.4 \%) .{ }^{37}$ No patient died during the course of the study. Treatment-emergent SAEs were reported in $10.6 \%$ of ZOL recipients compared with $9.8 \%$ of ALN recipients; no SAEs were considered to be study drug related. Only 3.5\% ZOL recipients and 0.9\% ALN recipients discontinued treatment because of AEs. Within the first 3 days of initial drug administration, treatment-emergent AEs occurred in $36.3 \%$ of ZOL recipients compared with $21.4 \%$ of ALN recipients (Table 2 ). Three or more days after initial administration, the incidence of treatment-emergent
AEs was broadly similar in ZOL and ALN recipients $(77.9 \%$ vs $73.2 \%$ of patients). ${ }^{37}$

Safety results from a study by Saag et $\mathrm{al}^{38}$ showed that a comparable proportion of patients reported AEs in each treatment group (ZOL $5 \mathrm{mg}, 91.3 \%$; ALN $70 \mathrm{mg}, 86.4 \%$ ). Transient, flu-like symptoms were the most common AEs in the ZOL group and resulted in a higher frequency of AEs in the group during the first 3 days of treatment (Table 2). After 3 days, AE rates were similar in both groups $(79.7 \%$ ZOL vs $78.0 \%$ ALN). There were no deaths during this study. SAEs occurred in 2 patients in the ZOL group (osteoarthritis, chest pain) and 3 patients in the ALN group (1 patella fracture, 2 osteoarthritis). None were considered related to the treatment.

\section{ZOL vs RIS}

Safety data from a comparative trial of 1-year duration that tested the effectiveness of once-yearly IV ZOL $5 \mathrm{mg}$ vs daily oralRIS $30 \mathrm{mg}$, for the prevention and treatment of GIO, showed that the overall incidence of SAEs was similar between the ZOL and RIS groups, but AEs were more common with ZOL than with RIS largely as a result of transient, flu-like symptoms during the first 3 days after infusion (Table 2). ${ }^{59}$

In the treatment subgroup, the most frequently reported SAE for patients tested with ZOL and RIS was worsening rheumatoid arthritis, which was judged to be severe in $2 \%$ of patients in each drug group.

In the prevention subgroup, the most frequently reported SAE was pyrexia, which was judged to be severe in $1 \%$ of patients in each drug group. No signifcant 
differences were recorded between the drug groups in either the treatment or the prevention subgroups within the cardiac disorders. ${ }^{59}$ In the treatment subgroup, the incidence of death was comparable between ZOL and RIS, (1\% ZOL vs 1\% RIS). However, in the prevention subgroup, it was slightly higher in the ZOL vs RIS groups (1\% ZOL vs $0 \%$ RIS).

In a study by Reid et $\mathrm{al}^{65}$ comparing ZOL with RIS in patients with Paget's disease, the number of patients with AEs (146 ZOL vs 133 RIS; Table 2) and SAEs (9 ZOL vs 11 RIS) were similar in the 2 groups. In the first 3 days, the ZOL group had twice the number of AEs as compared to the RIS group $(P<0.001)$, and these were principally the flu-like symptoms, known to occur in association with the IV use of nitrogen-containing bisphosphonates (Table 2). Subsequently, the rates of AEs were similar in the 2 groups. The frequencies of gastrointestinal and renal or urinary disorders were similar in the 2 groups. An 18-month extension of the study showed that death rates and SAEs were similar between ZOL and RIS. ${ }^{66}$

\section{Patient considerations and treatment preference}

Several large clinical trials have shown the efficacy of bisphosphonates in the treatment of osteoporosis. However, the long-term treatment with bisphosphonates is required for optimal and sustained benefit. Therefore, compliance and adherence to prescribed medication are needed for an evaluable therapeutic benefit to patients. ${ }^{76}$

In the treatment of osteoporosis, nonadherence to bisphosphonate therapy correlates with reduced gains in BMD and lower reductions in the levels of BTMs. ${ }^{77,78}$ In addition, nonadherence leads to an increased incidence of secondary complications associated with fractures, such as pain,

Table 2 Summary of five most frequently reported AEs after first infusion of ZOL in the treatment of osteoporosis and Paget's disease compared with placebo, ALN and RIS

\begin{tabular}{|c|c|c|c|c|c|c|c|c|}
\hline \multirow[t]{2}{*}{ Study } & \multirow[t]{2}{*}{ Intervention } & \multirow[t]{2}{*}{$\mathbf{N}$} & \multirow{2}{*}{$\begin{array}{l}\text { Any AE, } \\
\text { n (\%) }\end{array}$} & \multicolumn{5}{|c|}{ Five typical AEs within 3 days of initial dosinga } \\
\hline & & & & $\begin{array}{l}\text { Pyrexia, } \\
\text { n (\%) }\end{array}$ & $\begin{array}{l}\text { Myalgia, } \\
\text { n (\%) }\end{array}$ & $\begin{array}{l}\text { Influenza-like } \\
\text { symptoms, } \\
\text { n (\%) }\end{array}$ & $\begin{array}{l}\text { Headache, } \\
\mathrm{n}(\%)\end{array}$ & $\begin{array}{l}\text { Arthralgia, } \\
\mathrm{n}(\%)\end{array}$ \\
\hline \multicolumn{9}{|l|}{ ZOL vs placebo } \\
\hline \multirow[t]{7}{*}{ Reid et $\mathrm{al}^{25}$} & ZOL & & & & & & & \\
\hline & $4 \times 0.25 \mathrm{mg}$ & 60 & $52(87)$ & $6(10)$ & $12(20)$ & I (2) & Not reported & $9(15)$ \\
\hline & $4 \times 0.5 \mathrm{mg}$ & 58 & $50(86)$ & $5(9)$ & $6(10)$ & $4(7)$ & & $8(14)$ \\
\hline & $4 \times 1 \mathrm{mg}$ & 53 & $50(94)$ & $7(\mid 3)$ & $7(13)$ & $2(4)$ & & $9(17)$ \\
\hline & $2 \times 2 \mathrm{mg}$ & 61 & $56(92)$ & $12(20)$ & $10(16)$ & $10(16)$ & & $15(25)$ \\
\hline & $\mathrm{I} \times 4 \mathrm{mg}$ & 60 & $54(90)$ & $9(15)$ & $6(10)$ & $9(15)$ & & $5(8)$ \\
\hline & Placebo & 59 & $45(76)$ & $2(3)$ & I (2) & $4(7)$ & Not reported & $9(15)$ \\
\hline Black et $\mathrm{al}^{28}$ & ZOL $5 \mathrm{mg}$ & 3862 & $3688(95.5)$ & $621(16.1)$ & $365(9.5)$ & $30 I(7.8)$ & $273(7.1)$ & $245(6.3)$ \\
\hline (HORIZON-PFT) & Placebo & 3852 & $3616(93.9)$ & $79(2.1)$ & $66(1.7)$ & $61(1.6)$ & $90(2.3)$ & $76(2.0)$ \\
\hline Lyles et $\mathrm{al}^{43}$ & ZOL $5 \mathrm{mg}$ & 1054 & $867(82.3)$ & $73(6.9)$ & $33(3.1)$ & $6(0.6)$ & $16(1.5)$ & $33(3.1)$ \\
\hline (HORIZON-RFT) & Placebo & 1057 & $852(80.6)$ & $9(0.9)$ & $9(0.9)$ & $3(0.3)$ & $9(0.9)$ & $23(2.2)$ \\
\hline \multicolumn{9}{|l|}{ ZOL vs ALN } \\
\hline \multirow[t]{2}{*}{ McClung et $\mathrm{al}^{37}$} & ZOL $5 \mathrm{mg}$ & 113 & $98(86.7)$ & Not reported & Not reported & Not reported & $14(12.4)$ & $6(5.3)$ \\
\hline & ALN $70 \mathrm{mg}$ & 112 & $90(80.4)$ & Not reported & Not reported & Not reported & $7(6.3)$ & I (0.9) \\
\hline \multirow[t]{2}{*}{ Saag et $\mathrm{al}^{38}$} & ZOL & 69 & $63(91.3)$ & $4(5.8)$ & $8(11.6)$ & $13(18.8)$ & $5(7.2)$ & $5(7.2)$ \\
\hline & ALN $70 \mathrm{mg}$ & 59 & $51(86.4)$ & I (I.7) & I (I.7) & $3(5.1)$ & $7(11.9)$ & $4(6.8)$ \\
\hline \multicolumn{9}{|l|}{ ZOL vs RIS } \\
\hline \multirow[t]{2}{*}{ Reid et al ${ }^{65}$} & ZOL 5 mg & 177 & $146(82.5)$ & $13(7.3)$ & $13(7.3)$ & $17(9.6)$ & $12(6.8)$ & Not reported \\
\hline & RIS $30 \mathrm{mg}$ & 172 & I33 (77.3) & I (0.6) & $6(3.5)$ & $7(4.1)$ & $7(4.1)$ & Not reported \\
\hline Reid et al ${ }^{59}$ & ZOL 5 mg & 272 & $211(78)$ & $32(12)$ & $29(11)$ & $15(6)$ & $13(5)$ & $32(12)$ \\
\hline (Treatment group) & RIS 30 mg & 273 & $186(68)$ & $12(4)$ & $6(2)$ & $3(1)$ & $5(2)$ & $21(8)$ \\
\hline Reid et $\mathrm{al}^{59}$ & ZOL $5 \mathrm{mg}$ & 144 & III (77) & $21(15)$ & $9(6)$ & $10(7)$ & $9(6)$ & $9(6)$ \\
\hline (Prevention group) & RIS 30 mg & 144 & $93(65)$ & $3(2)$ & $8(6)$ & $\mathrm{I}(\mathrm{I})$ & $5(3)$ & $10(7)$ \\
\hline
\end{tabular}

Note: ${ }^{\text {a The }} 5$ symptoms listed were the most frequently cited in Black et al ${ }^{28}$ and other studies.

Abbreviations: AE, adverse event; ZOL, zoledronic acid; ALN, alendronate; RIS, risedronate; N, number of patients; HORIZON-PFT, The Health Outcomes and Reduced Incidence with Zoledronic Acid Once Yearly-Pivotal Fracture Trial; HORIZON-RFT, HORIZON-Recurrent Fracture Trial. 
nosocomial infections, and pulmonary thromboembolism, and hence to a decreased QoL. ${ }^{78-81}$

\section{Reasons for the suboptimal adherence to earlier developed bisphosphonates}

The main reasons patients cite for not continuing to take their osteoporosis medication are the stringent dosing schedule, AEs, not feeling that treatment is working, and not believing that they have a disease that needs to be treated. ${ }^{76}$ The commonest reasons were the strict dosing requirements for oral bisphosphonates (fasting overnight or for at least 6 hours prior to taking the medication and 30-60 min after administration) and posture (staying upright for 30-60 minutes after taking the medication), which can be inconvenient and often not feasible in the daily routine. The second most common reason for discontinuation of therapy is side effects. The main complaints with oral bisphosphonates are upper gastrointestinal irritation, dyspepsia, nausea, upper abdominal pain, vomiting, and gastroesophageal reflux. Finally, as patients often have no symptoms until they suffer a fracture, they do not feel that treatment is worth taking or do not believe they have a disease that needs treatment. They may consider the pill a burden and the inconvenience of the dosing requirements to be unnecessary. ${ }^{76}$

\section{Evolution of dosing regimens to overcome nonadherence}

Initially, all the studies for oral bisphosphonates (ALN, RIS, and ibandronate), which showed antifracture efficacy, were conducted using a daily regimen. ${ }^{29-31,33,82}$ However, the burdensome dosing requirements needed for gastrointestinal protection with daily oral bisphosphonates led to the development of less-frequent oral regimens. As the half-life of bone-bound bisphosphonates is long, weekly dosing of bisphosphonates is possible; moreover, they remain at resorption sites longer than the 2-week lifespan of individual osteoclasts. ${ }^{83}$ Weekly oral ALN and RIS achieved approval based on comparisons with the respective daily regimens. ${ }^{84,85}$ Weekly oral ibandronate has also shown noninferior efficacy to the daily regimen ${ }^{86}$ but has not been marketed. Bisphosphonate pharmacology also makes possible monthly, intermittent, quarterly, or yearly dosing. To improve adherence and persistence, these extended interval regimens were developed. Monthly oral ibandronate, the first approved monthly bisphosphonate regimen, was supported by comparison trials with the daily regimen and is in use since 2005. ${ }^{34,87}$ An intermittent oral RIS regimen ( 2 consecutive days monthly) was approved in April 2007, ${ }^{88}$ and a once-monthly RIS dosing regimen was approved in April 2008. ${ }^{89}$

Intravenous bisphosphonate regimens do not require stringent dosing requirements as oral bisphosphonates, and therefore, it provides alternative options for osteoporosis patients unable to take oral bisphosphonates. Quarterly IV ibandronate injection ( $3 \mathrm{mg} / 3$ months) became, in 2006 , the first IV bisphosphonate to be approved for PMO in the United States and in the EU. Quarterly IV ibandronate has shown efficacy in PMO with a similar safety profile to the monthly oral regimen. ${ }^{90}$ This was followed by once-yearly ZOL $5 \mathrm{mg}$ IV, which is approved globally for up to 6 indications in osteoporosis. It provides the greatest extended dosing interval and reduces concerns about oral administration, gastrointestinal intolerance, and bioavailability. The efficacy and safety of ZOL have been demonstrated from several large randomized trials. ${ }^{28,37,38,43}$

\section{Patient preference for once-yearly ZOL dosing}

A once-yearly IV ZOL has been preferred by a majority of trial outpatients in 2 separate trials, who switched to ZOL from weekly oral ALN. ${ }^{37,38}$ McClung et al ${ }^{37}$ reported that $79 \%$ of patients preferred an annual infusion of $\mathrm{ZOL}$ vs weekly oral ALN. Similarly, Saag et $\mathrm{al}^{38}$ reported that a majority of patients (66\%) preferred for annual ZOL vs weekly ALN. Moreover, patients who cannot tolerate or do not prefer oral dosing may opt for yearly IV infusion of $\mathrm{ZOL} .{ }^{28}$ Intravenous regimens may also be particularly advantageous for elderly patients residing in long-term care facilities or those with impairments affecting selfmanagement of medication. ${ }^{91}$

\section{Optimizing the dosing interval for ZOL}

Optimizing the dosing interval for ZOL is important. It is likely that even less frequent administration of ZOL will become more acceptable to patients and hence associated with greater adherence to long-term therapy. It has been demonstrated that the duration of antiresorptive action of a single 5-mg dose of ZOL exceeds 12 months, and it would be worth evaluating the antifracture efficacy of ZOL with a dosing interval of more than 12 months. ${ }^{92}$ 


\section{Place of ZOL in the treatment of osteoporosis}

In randomized clinical trials, ZOL $5 \mathrm{mg}$ has been proven to be effective in reducing the risk of vertebral, nonvertebral and hip fractures, and to be generally well tolerated in $\mathrm{PMO}^{28} \mathrm{ZOL}$ is the only bisphosphonate to have demonstrated significant risk reduction at all major osteoporotic fracture sites. The $70 \%$ relative risk reduction in vertebral fracture at 3 years demonstrated by once-yearly ZOL $5 \mathrm{mg}^{28}$ is numerically greater than the relative risk reductions shown by ALN (44\%) ${ }^{82}$ or RIS (49\%). ${ }^{93}$ ZOL $5 \mathrm{mg}$ has also been shown to be effective in the prevention of clinical fracture in patients (male and female) who have previously experienced a low-trauma hip fracture. ${ }^{43} \mathrm{ZOL}$ $5 \mathrm{mg}$ is the only agent with demonstrated efficacy in this indication. ZOL is also significantly more effective than RIS in preventing and treating GIO. ${ }^{59}$ Most recently, the efficacy of ZOL in treating osteoporosis in men has also been demonstrated..$^{47,48}$ The formulation and administration regimen of ZOL $5 \mathrm{mg}$ ensures year-long effectiveness. Thus, it presents an attractive alternative to other daily, weekly, or monthly bisphosphonate therapies. Moreover, several studies are underway to determine the efficacy of ZOL compared with other bisphosphonates, ie, ZOL is being compared with pamidronate in heart- and lung-transplantrelated osteopenia and osteoporosis, with ALN in heart and liver transplantations and with ALN in kidney and kidney/ pancreas transplantations. ${ }^{94}$

\section{Conclusions}

The main aim of treatment in osteoporosis is to reduce the risk of fractures, thereby reducing fracture-associated morbidity and mortality. A once-yearly administration of ZOL $5 \mathrm{mg}$ has the potential to help meet this main clinical need of patients with osteoporosis because clinical evidence suggests that it is more effective than oral bisphosphonates in reducing the risk of vertebral and hip fractures, and it improves compliance through provision of medication over the entire 1-year period in a formulation that is well tolerated.

\section{Review criteria}

Searches were performed using PubMed to find material published in English between 2000 and 2009. We used the search terms zoledronic acid, bisphosphonates, osteoporosis, secondary osteoporosis, clinical utility, adherence, patient preference, and Paget's disease to find full-text articles and abstracts. Reference lists from various articles were also searched for further sources.

\section{Abbreviations}

$\mathrm{AE}$, adverse event; $\mathrm{AF}$, atrial fibrillation; $\mathrm{ALN}$, alendronate; BAP, bone alkaline phosphatase; BCE, bone collagen equivalents; BMD, bone mineral density; BSAP, bone specific alkaline phosphatase; BTMs, bone turn over markers; CTx, Serum type I collagen C telopeptide; DXA, dual energy X-ray absorptiometry; EU, European Union; GIO, glucocorticoidinduced osteoporosis; HCM, hypercalcemia of malignancy; HORIZON-PFT, The Health Outcomes and Reduced Incidence with Zoledronic Acid Once Yearly-Pivotal Fracture Trial; HORIZON-RFT, The Health Outcomes and Reduced Incidence with Zoledronic Acid Once Yearly-Recurrent Fracture Trial; IV, intravenous; LTO, localized transient osteoporosis; NTx, N-telopeptide of type I collagen; ONJ, osteonecrosis of the jaw; P1NP, serum N-terminal propeptide of type I collagen; PMO, postmenopausal osteoporosis; QoL, quality of life; RIS, risedronate; SAE, serious adverse event; SAP, serum alkaline phosphatase; SE, standard error; SRE, skeletal-related event; US, United States of America; VAS, visual analog scale; WHO, World Health Organization; ZOL, zoledronic acid.

\section{Acknowledgment}

The author wishes to thank Swati Machwe (Novartis Healthcare Pvt. Ltd., India) for providing editorial support during the preparation of the manuscript.

\section{Disclosure}

The author has served in the past as an advisor and given lectures for Novartis and other companies in the field of osteoporosis.

\section{References}

1. Reginster JY, Burlet N. Osteoporosis: a still increasing prevalence. Bone. 2006;38(2 Suppl 1):S4-S9.

2. Rotella DP. Osteoporosis: challenges and new opportunities for therapy. Curr Opin Drug Discov Devel. 2002;5(4):477-486.

3. Bonura F. Prevention, screening, and management of osteoporosis: an overview of the current strategies. Postgrad Med. 2009;121(4): $5-17$.

4. WHO. Prevention and management of osteoporosis. World Health Organ Tech Rep Ser. 2003;921:1-164.

5. Kanis JA, Oden A, Johnell O, et al. The use of clinical risk factors enhances the performance of BMD in the prediction of hip and osteoporotic fractures in men and women. Osteoporos Int. 2007;(8): 1033-1046.

6. Kanis J. FRAXTM WHO fracture risk assessment tool. http://wwwshefacuk/FRAX/ indexhtm. Accessed September15, 2009.

7. Bonnick SL, Shulman L. Monitoring osteoporosis therapy: bone mineral density, bone turnover markers, or both? Am J Med. 2006;119 (4 Suppl 1):S25-S31.

8. Curtis JR, Westfall AO, Cheng H, Delzell E, Saag KG. Risk of hip fracture after bisphosphonate discontinuation: implications for a drug holiday. Osteoporos Int. 2008;19(11):1613-1620. 
9. Eastell R. Treatment of postmenopausal osteoporosis. $N$ Engl J Med. 1998;338(11):736-746.

10. Barrett J, Worth E, Bauss F, Epstein S. Ibandronate: a clinical pharmacological and pharmacokinetic update. J Clin Pharmacol. 2004;44(9): 951-965.

11. Waknine Y. Zoledronic acid injection approved to prevent postmenopausal osteoporosis. 2009; Available from: http:/www.medscape.com/ viewarticle/703898 Accessed December 31, 2009.

12. FDA Approves Zometa (Zoledronic Acid) for Hypercalcemia of Malignancy. Available at: http://www.docguide.com/news/content.nsf/news/ 00EF3B1D01A2414585256AAF004B4646. Accessed May 26, 2010.

13. Li EC, Davis LE. Zoledronic acid: a new parenteral bisphosphonate. Clin Ther. 2003;25(11):2669-2708.

14. Keating GM, Scott LJ. Zoledronic acid: a review of its use in the treatment of Paget's disease of bone. Drugs. 2007;67(5):793-804.

15. Deeks ED, Perry CM. Zoledronic acid: a review of its use in the treatment of osteoporosis. Drugs Aging. 2008;25(11): 963-986.

16. Wellington K, Goa KL. Zoledronic acid: a review of its use in the management of bone metastases and hypercalcaemia of malignancy. Drugs. 2003;63(4):417-437.

17. Ringe J. Zoledronic acid in the treatment of Paget's disease and other benign bone disorders. Expert Rev Endocrinol Metab. 2006;1(1): 15-24.

18. Russell RG. Bisphosphonates: from bench to bedside. Ann N Y Acad Sci. 2006;1068:367-401.

19. Nancollas GH, Tang R, Phipps RJ, et al. Novel insights into actions of bisphosphonates on bone: differences in interactions with hydroxyapatite. Bone. 2006;38(5):617-627.

20. Coxon FP, Helfrich MH, Van't Hof R, et al. Protein geranylgeranylation is required for osteoclast formation, function, and survival: inhibition by bisphosphonates and GGTI-298. J Bone Miner Res. 2000;15(8): 1467-1476.

21. Fromigue O, Body JJ. Bisphosphonates influence the proliferation and the maturation of normal human osteoblasts. $J$ Endocrinol Invest. 2002;25(6):539-546.

22. von Knoch F, Jaquiery C, Kowalsky M, et al. Effects of bisphosphonates on proliferation and osteoblast differentiation of human bone marrow stromal cells. Biomaterials. 2005;26(34):6941-6949.

23. Kavanagh KL, Guo K, Dunford JE, et al. The molecular mechanism of nitrogen-containing bisphosphonates as antiosteoporosis drugs. Proc Natl Acad Sci U S A. 2006;103(20):7829-7834.

24. Dunford JE, Thompson K, Coxon FP, et al. Structure-activity relationships for inhibition of farnesyl diphosphate synthase in vitro and inhibition of bone resorption in vivo by nitrogen-containing bisphosphonates. J Pharmacol Exp Ther. 2001;296(2):235-242.

25. Reid IR, Brown JP, Burckhardt $P$, et al. Intravenous zoledronic acid in postmenopausal women with low bone mineral density. $N$ Engl J Med. 2002;346(9):653-661.

26. Devogelaer JP, Brown JP, Burckhardt P, et al. Zoledronic acid efficacy and safety over five years in postmenopausal osteoporosis. Osteoporos Int. 2007;18(9):1211-1218.

27. Recker R, Stakkestad JA, Chesnut CH, et al. Insufficiently dosed intravenous ibandronate injections are associated with suboptimal antifracture efficacy in postmenopausal osteoporosis. Bone. 2004;34(5):890-899.

28. Black DM, Delmas PD, Eastell R, et al. Once-yearly zoledronic acid for treatment of postmenopausal osteoporosis. NEngl J Med. 2007;356(18): 1809-1822.

29. Harris ST, Watts NB, Genant HK, et al. Effects of risedronate treatment on vertebral and nonvertebral fractures in women with postmenopausal osteoporosis: a randomized controlled trial. Vertebral Efficacy With Risedronate Therapy (VERT) Study Group. Jama. 1999;282(14): 1344-1352.

30. Reginster J, Minne HW, Sorensen OH, et al. Randomized trial of the effects of risedronate on vertebral fractures in women with established postmenopausal osteoporosis. Vertebral Efficacy with Risedronate Therapy (VERT) Study Group. Osteoporos Int. 2000;11(1):83-91.
31. Chesnut IC, Skag A, Christiansen C, et al. Effects of oral ibandronate administered daily or intermittently on fracture risk in postmenopausal osteoporosis. J Bone Miner Res. 2004;19(8):1241-1249.

32. Siris E, Adachi JD, Lu Y, et al. Effects of raloxifene on fracture severity in postmenopausal women with osteoporosis: results from the MORE study. Multiple Outcomes of Raloxifene Evaluation. Osteoporos Int. 2002;13(11):907-913.

33. Black DM, Cummings SR, Karpf DB, et al. Randomised trial of effect of alendronate on risk of fracture in women with existing vertebral fractures. Fracture Intervention Trial Research Group. Lancet. 1996; 348(9041):1535-1541.

34. Miller PD, McClung MR, Macovei L, et al. Monthly oral ibandronate therapy in postmenopausal osteoporosis: 1-year results from the MOBILE study. J Bone Miner Res. 2005;20(8):1315-1322.

35. Reginster JY, Wilson KM, Dumont E, Bonvoisin B, Barrett J. Monthly oral ibandronate is well tolerated and efficacious in postmenopausal women: results from the monthly oral pilot study. $J$ Clin Endocrinol Metab. 2005;90(9):5018-5024.

36. Recker RR, Delmas PD, Halse J, et al. Effects of intravenous zoledronic acid once yearly on bone remodeling and bone structure. J Bone Miner Res. 2008;23(1):6-16.

37. McClung M, Recker R, Miller P, et al. Intravenous zoledronic acid 5 $\mathrm{mg}$ in the treatment of postmenopausal women with low bone density previously treated with alendronate. Bone. 2007;41(1):122-128.

38. Saag K, Lindsay R, Kriegman A, Beamer E, Zhou W. A single zoledronic acid infusion reduces bone resorption markers more rapidly than weekly oral alendronate in postmenopausal women with low bone mineral density. Bone. 2007;40(5):1238-1243.

39. McClung M, Miller P, Recknor C, Mesenbrink P, Bucci-Rechtweg C, Benhamou CL. Zoledronic acid for the prevention of bone loss in postmenopausal women with low bone mass. Obstet Gynecol. 2009;114(5):1-9.

40. Grey A, Bolland MJ, Wattie D, Horne A, Gamble G, Reid IR. The antiresorptive effects of a single dose of zoledronate persist for two years: a randomized, placebo-controlled trial in osteopenic postmenopausal women. J Clin Endocrinol Metab. 2009;94(2):538-544.

41. Boonen S, Autier P, Barette M, Vanderschueren D, Lips P, Haentjens P. Functional outcome and quality of life following hip fracture in elderly women: a prospective controlled study. Osteoporos Int. 2004;15(2):87-94.

42. Colon-Emeric C, Kuchibhatla M, Pieper C, et al. The contribution of hip fracture to risk of subsequent fractures: data from two longitudinal studies. Osteoporos Int. 2003;14(11):879-883.

43. Lyles KW, Colon-Emeric CS, Magaziner JS, et al. Zoledronic acid and clinical fractures and mortality after hip fracture. $N$ Engl J Med. 2007;357:1799-1809.

44. Eriksen EF, Lyles KW, Colon-Emeric CS, et al. Antifracture efficacy and reduction of mortality in relation to timing of the first dose of zoledronic acid after hip fracture. J Bone Miner Res. 2009;24(7): 1308-1313.

45. Haney EM, Bliziotes MM. Male osteoporosis: new insights in an understudied disease. Curr Opin Rheumatol. 2008;20(4):423-428.

46. Boonen S, Magaziner J, Lyles KW, et al. Effect of once-yearly i.v. zoledronic acid in men after hip fracture: results from the horizon-recurrent fracture trial [abstract no. P251]. Osteoporos Int. 2009;20 Suppl 1: S23-S176.

47. Colon-Emeric CS, Mesenbrink P, Lyles KW, et al. Potential mediators of the mortality reduction with zoledronic acid after hip fracture. J Bone Miner Res. 2009;25(1):91-97.

48. Orwoll E, Miller P, Adachi J, et al. Once-yearly i.v. zoledronic acid 5 $\mathrm{mg}$ versus weekly oral alendronate $70 \mathrm{mg}$ in men with osteoporosis. In: ENDO 2009Abstracts2View Online. Abstract OR13-3. Chevy Chase, MD: The Endocrine Society; 2009. http://www.endo-society. org/endo09/. Accessed February 1, 2010.

49. Letocha AD, Cintas HL, Troendle JF, et al. Controlled trial of pamidronate in children with types III and IV osteogenesis imperfecta confirms vertebral gains but not short-term functional improvement. J Bone Miner Res. 2005;20(6):977-986. 
50. Dimeglio LA, Ford L, McClintock C, Peacock M. A comparison of oral and intravenous bisphosphonate therapy for children with osteogenesis imperfecta. J Pediatr Endocrinol Metab. 2005;18(1):43-53.

51. Seikaly MG, Kopanati S, Salhab N, et al. Impact of alendronate on quality of life in children with osteogenesis imperfecta. $J$ Pediatr Orthop. 2005;25(6):786-791.

52. Brown JJ, Zacharin MR. Safety and efficacy of intravenous zoledronic acid in paediatric osteoporosis. J Pediatr Endocrinol Metab. 2009;22(1): $55-63$.

53. Boonen S, Black DM, Colón-Emeric CS, et al. Efficacy and safety of a once-yearly intravenous zoledronic acid $5 \mathrm{mg}$ for fracture prevention in elderly osteoporotic postmenopausal women aged 75 years and older. J Am Geriatr Soc. 2010;58(2):292-299.

54. Van Staa TP, Leufkens HG, Abenhaim L, Zhang B, Cooper C. Oral corticosteroids and fracture risk: relationship to daily and cumulative doses. Rheumatology (Oxford). 2000;39(12):1383-1389.

55. Van Staa TP, Leufkens HG, Abenhaim L, Zhang B, Cooper C. Use of oral corticosteroids and risk of fractures. J Bone Miner Res. 2000;15(6): 993-1000.

56. Van Staa TP, Leufkens HG, Cooper C. The epidemiology of corticosteroid-induced osteoporosis: a meta-analysis. Osteoporos Int. 2002;13(10):777-787.

57. Devogelaer JP, Goemaere S, Boonen S, et al. Evidence-based guidelines for the prevention and treatment of glucocorticoid-induced osteoporosis: a consensus document of the Belgian Bone Club. Osteoporos Int. 2006; 17(1):8-19.

58. American College of Rheumatology Ad Hoc Committee on GlucocorticoidInduced Osteoporosis. Recommendations for the prevention and treatment of glucocorticoid-induced osteoporosis: 2001 update. American College of Rheumatology Ad Hoc Committee on Glucocorticoid-Induced Osteoporosis. Arthritis Rheum. 2001;44(7): 1496-1503.

59. Reid DM, Devogelaer JP, Saag K, et al. Zoledronic acid and risedronate in the prevention and treatment of glucocorticoid-induced osteoporosis (HORIZON): a multicentre, double-blind, double-dummy, randomised controlled trial. Lancet. 2009;373(9671):1253-1263.

60. Otrock ZK, Azar ST, Shamseddeen WA, et al. Intravenous zoledronic acid treatment in thalassemia-induced osteoporosis: results of a phase II clinical trial. Ann Hematol. 2006;85(9):605-609.

61. Otrock ZK, Mahfouz RA, Charafeddine KM, Rayes RF, Zahed LF, Taher AT. Vitamin D receptor genotypes and response to zoledronic acid therapy in thalassemia-induced osteoporosis. Ann Hematol. 2008;87(11):947-948.

62. Voskaridou E, Anagnostopoulos A, Konstantopoulos K, et al. Zoledronic acid for the treatment of osteoporosis in patients with beta-thalassemia: results from a single-center, randomized, placebocontrolled trial. Haematologica. 2006;91(9):1193-1202.

63. Voskaridou E, Christoulas D, Konstantinidou M, Tsiftsakis E, Alexakos P, Terpos E. Continuous improvement of bone mineral density two years post zoledronic acid discontinuation in patients with thalassemia-induced osteoporosis: long-term follow-up of a randomized, placebo-controlled trial. Haematologica. 2008;93(10): $1588-1590$

64. Ringe JD, Farahmand P, Dorst A. Intravenous zoledronic acid: a rapid and very effective treatment in localized transient osteoporosis of the hip. Osteologie. 2007;16:28.

65. Reid IR, Miller P, Lyles K, et al. Comparison of a single infusion of zoledronic acid with risedronate for Paget's disease. $N$ Engl $J$ Med. 2005;353(9):898-908.

66. Hosking D, Lyles K, Brown JP, et al. Long-term control of bone turnover in Paget's disease with zoledronic acid and risedronate. $J$ Bone Miner Res. 2007;22(1):142-148.

67. Mercadante S. Malignant bone pain: pathophysiology and treatment. Pain. 1997;69(1-2):1-18.

68. Saad F, Gleason DM, Murray R, et al. A randomized, placebo-controlled trial of zoledronic acid in patients with hormone-refractory metastatic prostate carcinoma. J Natl Cancer Inst. 2002;94(19):1458-1468.
69. Rosen LS, Gordon D, Kaminski M, et al. Zoledronic acid versus pamidronate in the treatment of skeletal metastases in patients with breast cancer or osteolytic lesions of multiple myeloma: a phase III, double-blind, comparative trial. Cancer J. 2001;7(5):377-387.

70. Rosen LS, Gordon D, Kaminski M, et al. Long-term efficacy and safety of zoledronic acid compared with pamidronate disodium in the treatment of skeletal complications in patients with advanced multiple myeloma or breast carcinoma: a randomized, double-blind, multicenter, comparative trial. Cancer. 2003;98(8):1735-1744.

71. Rosen LS, Gordon D, Tchekmedyian S, et al. Zoledronic acid versus placebo in the treatment of skeletal metastases in patients with lung cancer and other solid tumors: a phase III, double-blind, randomized trial - the Zoledronic Acid Lung Cancer and Other Solid Tumors Study Group. J Clin Oncol. 2003;21(16):3150-3157.

72. Bhoopalam N, Campbell SC, Moritz T, et al. Intravenous zoledronic acid to prevent osteoporosis in a veteran population with multiple risk factors for bone loss on androgen deprivation therapy. J Urol. 2009; 182(5):2257-2264

73. Zoledronic acid in prevention of aromatase inhibitor-associated bone loss (AIBL) in postmenopausal women. AHFS Drug Information ${ }^{\circledR}$ Off-label Use Determinations. 2008. Available from: http://www. ahfsdruginformation.com/off_label/tables/Zoledronic_Acid.pdf. Accessed May 26, 2010.

74. Demontiero O, Duque G. Once-yearly zoledronic acid in hip fracture prevention. Clin Interv Aging. 2009;4(1):153-164.

75. Grbic JT, Landesberg R, Lin SQ, et al. Incidence of osteonecrosis of the jaw in women with postmenopausal osteoporosis in the health outcomes and reduced incidence with zoledronic acid once yearly pivotal fracture trial. J Am Dent Assoc. 2008;139(1):32-40.

76. Reginster JY, Rabenda V. Patient preference in the management of postmenopausal osteoporosis with bisphosphonates. Clin Interv Aging. 2006;1(4):415-423.

77. Eastell R, Garnero P, Vrijens B, et al. Influence of patient compliance with risedronate therapy on bone turnover marker and bone mineral density response: the IMPACT study. Calcif Tissue Int. 2003;72:408.

78. Sebaldt RJ, Shane L, Pham B, et al. Longer-term effectiveness outcomes of non-compliance and non-persistence with daily-regimen bisphosphonate therapy in patients with osteoporosis treated in tertiary specialist care. Osteoporos Int. 2004;15 Suppl 1:S107.

79. Caro JJ, Ishak KJ, Huybrechts KF, Raggio G, Naujoks C. The impact of compliance with osteoporosis therapy on fracture rates in actual practice. Osteoporos Int. 2004;15(12):1003-1008.

80. Harris ST, Siris E, Abbott T, Barr CE, Harris S, Rosen C. Reduced osteoporotic fracture risk in patients adherence to bisphosphonate therapy. Program and Abstracts of The Endocrine Society's 87th Annual Meeting; 2005 June 4-7; 2005:3-382.

81. Siris E, Harris S, Silverman S, Abbott T, Barr C, Rosen C. Adherence to bisphosphonates (BPs) is associated with reduced fracture risk in women with postmenopausal osteoporosis (PMO). Menopause. 2005;12:807.

82. Cummings SR, Black DM, Thompson DE, et al. Effect of alendronate on risk of fracture in women with low bone density but without vertebral fractures: results from the Fracture Intervention Trial. Jama. 1998; 280(24):2077-2082.

83. Bone HG, Adami S, Rizzoli R, et al. Weekly administration of alendronate: rationale and plan for clinical assessment. Clin Ther. 2000; 22(1): $15-28$.

84. Schnitzer T, Bone HG, Crepaldi G, et al. Therapeutic equivalence of alendronate $70 \mathrm{mg}$ once-weekly and alendronate $10 \mathrm{mg}$ daily in the treatment of osteoporosis. Alendronate Once-Weekly Study Group. Aging (Milano). 2000;12:1-12.

85. Brown JP, Kendler DL, McClung MR, et al. The efficacy and tolerability of risedronate once a week for the treatment of postmenopausal osteoporosis. Calcif Tissue Int. 2002;71(2):103-111.

86. Cooper C, Emkey RD, McDonald RH, et al. Efficacy and safety of oral weekly ibandronate in the treatment of postmenopausal osteoporosis. $J$ Clin Endocrinol Metab. 2003;88(10):4609-4615. 
87. Reginster JY, Adami S, Lakatos P, et al. Efficacy and tolerability of oncemonthly oral ibandronate in postmenopausal osteoporosis: 2 year results from the MOBILE study. Ann Rheum Dis. 2006;65(5):654-661.

88. Delmas PD, Benhamou CL, Man Z, et al. Monthly dosing of $75 \mathrm{mg}$ risedronate on 2 consecutive days a month: efficacy and safety results. Osteoporos Int. 2008;19(7):1039-1045.

89. Delmas PD, McClung MR, Zanchetta JR, et al. Efficacy and safety of risedronate $150 \mathrm{mg}$ once a month in the treatment of postmenopausal osteoporosis. Bone. 2008;42(1):36-42.

90. Delmas PD, Adami S, Strugala C, et al. Intravenous ibandronate injections in postmenopausal women with osteoporosis: one-year results from the dosing intravenous administration study. Arthritis Rheum. 2006;54(6):1838-1846.
91. Sunyecz J. Optimizing dosing frequencies for bisphosphonates in the management of postmenopausal osteoporosis: patient considerations. Clin Interv Aging. 2008;3(4):611-627.

92. Cramer JA, Gold DT, Silverman SL, Lewiecki EM. A systematic review of persistence and compliance with bisphosphonates for osteoporosis. Osteoporos Int. 2007;18(8):1023-1031.

93. Sorensen OH, Crawford GM, Mulder H, et al. Long-term efficacy of risedronate: a 5-year placebo-controlled clinical experience. Bone. 2003; 32(2):120-126.

94. Doggrell SA. Clinical efficacy and safety of zoledronic acid in prostate and breast cancer. Expert Rev Anticancer Ther. 2009;9(9): 1211-1218.

\section{Publish your work in this journal}

Patient Preference and Adherence is an international, peer-reviewed, open access journal that focusing on the growing importance of patient preference and adherence throughout the therapeutic continuum. Patient satisfaction, acceptability, quality of life, compliance, persistence and their role in developing new therapeutic modalities and compounds to optimize clinical outcomes for existing disease states are major areas of interest. This journal has been accepted for indexing on PubMed Central. The manuscript management system is completely online and includes a very quick and fair peer-review system. Visit http://www.dovepress.com/ testimonials.php to read real quotes from published authors.

Submit your manuscript here: http://www.dovepress.com/patient-preference-and-adherence-journal 